\title{
Subcutaneous granuloma annulare
}

\section{Lucía González Ruiz', María Rogel Vence', Mónica García Arpa1, Natalia Villasanti Rivas'², Prado Sánchez Caminero'}

${ }^{1}$ Department of Dermatology, Hospital General Universitario de Ciudad Real Ciudad Real, Spain, ${ }^{2}$ Department of Pathology, Hospital General Universitario de Ciudad Real Ciudad Real, Spain

Corresponding author: Dr. Lucía González Ruiz, E-mail: gruizlucia@gmail.com

\begin{abstract}
Granuloma annulare (GA) is a benign granulomatous skin disease. Subcutaneous granuloma annulare is a rare variant in adults, predominantly affects women and typically involves hands. Differential diagnosis should be made with rheumatoid nodules, which frecuently pose a challenge because of the clinical and histological resemblance. Histopathologically, subcutaneous granuloma annulare is a necrobiotic non-infectious granuloma surrounded by chronic inflammatory infiltrate. Treatment is not standarised, although topical or intralesional stereoids and surgery are used.
\end{abstract}

Key words: Granuloma annulare; Subcutaneous granuloma annulare; Rheumatoid nodules; Intralesional steroids 


\section{Granuloma anular subcutáneo}

\section{Lucía González Ruiz', María Rogel Vence', Mónica García Arpa', Natalia Villasanti Rivas², Prado Sánchez Caminero'}

${ }^{1}$ Department of Dermatology, Hospital General Universitario de Ciudad Real Ciudad Real, Spain, ${ }^{2}$ Department of Pathology, Hospital General Universitario de Ciudad Real Ciudad Real, Spain

Corresponding author: Dr. Lucía González Ruiz, E-mail: gruizlucia@gmail.com

\section{RÉSUMÉ}

El granuloma anular (GA) es una enfermedad cutánea granulomatosa poco frecuente, de carácter inflamatorio y benigno. La variante profunda o subcutánea es infrecuente en adultos y cuando se localiza en manos debe distinguirse de los nódulos reumatoideos, con los que tiene importantes similitudes clínicas e histológicas. Histológicamente, el GA profundo presenta formación de granulomas en empalizada localizados en dermis profunda y tejido celular subcutáneo. El tratamiento no está estandarizado, aunque se sugieren los corticoides tópicos o intralesionales, así como la cirugía.

Palabras clave: Granuloma anular; Granuloma anular subcutáneo; Nódulos reumatoideos; Corticoides intralesionales

\section{INTRODUCTION}

El granuloma anular profundo es una variante de granuloma anular poco frecuente en adultos, que suele afectar a mujeres de mediana edad. Se presenta como nódulos indoloros color piel, de predominio en miembros inferiores, manos o cuero cabelludo. Es fundamental hacer el diagnóstico diferencial con los nódulos reumatoides cuando las lesiones se localizan en las manos, ya que son entidades que clínicamente pueden ser indistinguibles.

\section{CASE SYNOPSIS}

Mujer de 54 años con antecedentes personales de hipotiroidismo en tratamiento con levotiroxina. Acudió a la consulta por lesiones asintomáticas de años de evolución localizadas en el dorso de la mano derecha. La paciente negaba clínica sistémica o articular asociada; así como lesiones cutáneas en otras localizaciones. Se trataba de nódulos eritematosas que medían entre 1 y $2 \mathrm{~cm}$ aproximadamente (Fig. 1). Tenían una superficie lisa y polilobulada, consistencia firme y no estaban adheridas a planos profundos. Las lesiones se localizaban en la superficie dorsal de la mano derecha sobre las articulaciones metacarpofalángicas e interfalángicas. La biopsia de la lesión mostró degeneración del colágeno formando granulomas, rodeados en algunas zonas de histiocitos en empalizada (Figs. 2a y 2b), con discreto aumento de mucinas. Se realizó una analítica que incluía reactantes de fase aguda (VSG y PCR), ANA y factor reumatoide (FR) que fue normal. La ecografía cutánea puso de manifiesto unas lesiones hipoecoicas localizadas en dermis y tejido celular subcutáneo, bien delimitadas y polilobuladas, próximas al periostio sin infiltración ósea (Fig. 3a). Las lesiones no mostraban flujo en modo Doppler (Fig. 3b).

Se realizó el diagnóstico de granuloma anular profundo o subcutáneo y se realizó tratamiento intralesional con $1 \mathrm{ml}$ de betametasona distribuido por las tres lesiones con importante mejoría de las mismas. Tras seis meses de seguimiento, la paciente se encuentra estable sin aparición de nuevos nódulos.

\section{DISCUSSION}

El granuloma anular (GA) es una enfermedad cutánea granulomatosa poco frecuente, de carácter

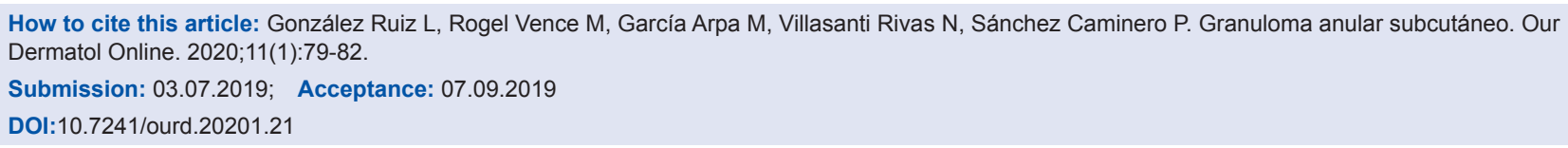




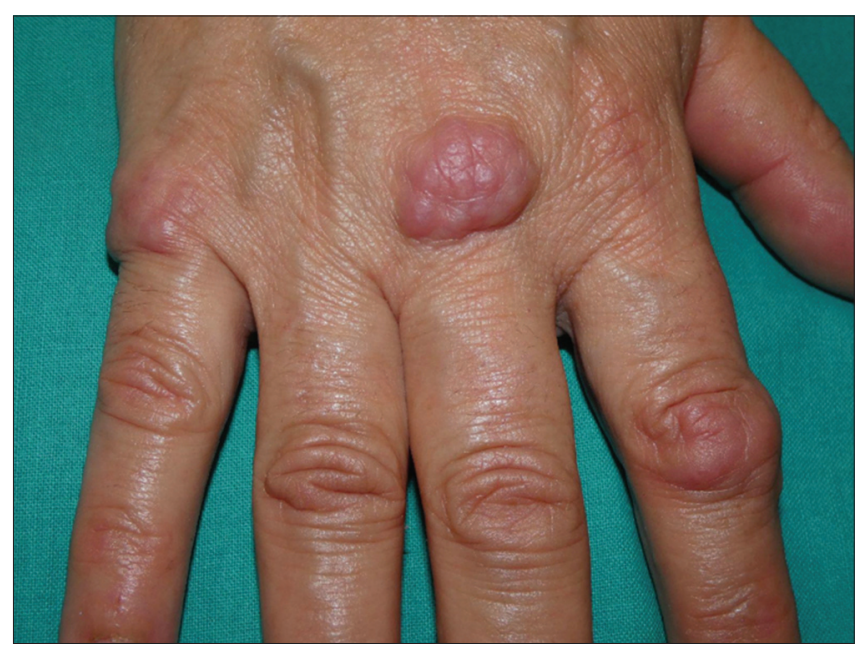

Figura 1: Nódulos eritematosos polilobulados de superficie lisa.

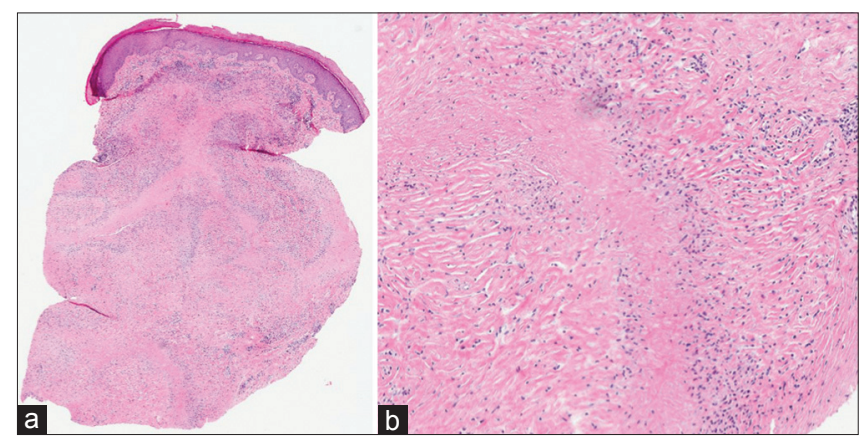

Figura 2: (a) A pequeño aumento se observan varios focos de colágeno degenerado a distintos niveles de la dermis (H\&E, x10) (b) Detalle de uno de los focos de colágeno degenerado rodeado de histiocitos dispuestos en empalizada, situado en la dermis profunda (H\&E, x40).

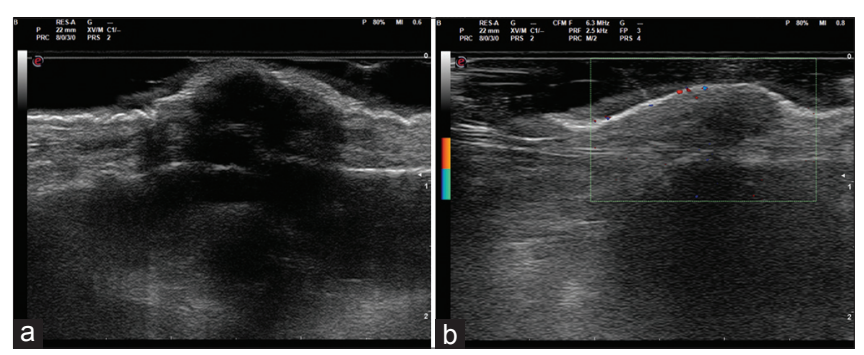

Figura 3: (a) Lesiones hipoecoicas localizadas en dermis y tejido celular subcutáneo, bien delimitadas y polilobuladas, próximas al periostio sin infiltración ósea (b) Ausencia de flujo en modo doppler.

inflamatorio y benigno. Se trata de una entidad de etiología desconocida y autolimitada, pero con recurrencias frecuentes. De entre las variantes de GA descritas, el GA profundo o subcutáneo ocupa el tercer lugar en frecuencia tras el GA localizado y el GA diseminado [1,2]. Característicamente, el GA profundo afecta a niños sanos menores de 5 años, y con menos frecuencia a adultos jóvenes [1-5]. El granuloma anular profundo o subcutáneo se presenta como nódulos indoloros color piel, de predominio en miembros inferiores, manos o cuero cabelludo [1-3]. El GA profundo es infrecuente en adultos y cuando se presenta suelen ser mujeres de mediana edad con lesiones localizadas en manos próximas a las pequeñas articulaciones [5]. En estos casos es fundamental hacer el diagnóstico diferencial con los nódulos reumatoides, entidades que clínica e histológicamente pueden ser indistinguibles. Otros cuadros que se deben incluir en el diagnóstico diferencial son paniculitis, necrosis grasa, granulomas infecciosos o reacciones a cuerpo extraño entre otros, en función de la historia clínica de la lesión $[1,2,4,5]$. Histológicamente, el GA profundo presenta formación de granulomas en empalizada localizados en dermis profunda y tejido celular subcutáneo. Típicamente tiene un mayor grado de necrobiosis y depósitos de mucina que las formas clásicas de GA, pero menos necrobiosis que la presente en nódulos reumatoideos $[1,2,4]$. Se ha visto que el GA profundo y los nódulos reumatoideos (NR) comparten características histológicas. Así, Mesara et al. describieron el término "nódulo seudorreumatoideo" para referirse a lesiones que clínica e histológicamente se asemejan a NR en pacientes sin datos de artritis reumatoide u otras enfermedades sistémicas [2,4-6]. Las publicaciones en relación al tratamiento de esta patología tienen una evidencia pobre, ya que en su mayoría de tratan de casos sueltos o series cortas de casos. El abanico de opciones es amplio, e incluye tanto tratamientos tópicos como sistémicos, pero es frecuente la persistencia o recurrencia de las lesiones. En el caso del GA profundo, la primera línea incluye los corticoides de alta potencia tópicos o intralesionales [5]. La alterantiva quirúrgica se reservaría para las lesiones yuxta-articulares que provoquen impotencia funcional [2].

\section{CONCLUSION}

El GA profundo es una variante infrecuente de GA. Cuando las lesiones se localizan en manos de mujeres de mediana edad, debe hacerse el diagnóstico diferencial con los nódulos reumatoides, para lo que nos debemos apoyar tanto en la negatividad del FR, como en la ausencia de clínica articular y en la histología.

\section{Consent}

The examination of the patient was conducted according to the Declaration of Helsinki principles. 
www.odermatol.com

\section{REFERENCES}

1. Wang J, Khachemoune A. Granuloma annulare: a focused review of therapeutic options. Am J Clin Dermatol 2018;19:333-44.

2. Țăranu T, Grigorovici M, Constantin M, Toader MP. Subcutaneous granuloma annulare. Acta Dermatovenerol Croat. 2017;25:292-4.

3. Felner EI, Steinberg JB, Weinberg AG. Subcutaneous granuloma annulare: a review of 47 cases. Pediatrics. 1997;100:965-7.

4. Requena L, Fernandez-Figueras MT. Subcutaneous granuloma annulare. Semin Cutan Med Surg. 2007;26:96-9.

5. Barzilai A, Huszar M, Shpiro D, Nass D, Trau H. Pseudorheumatoid nodules in adults: a yuxta-articular form of nodular granuloma annular. Am J Dermatopathol. 2005:27:1-5.

6. Mijlkovic J, Krajnc I. Subcutaneous granuloma annulare in an adult. Wien kiln Wochenschr. 2003;115:309-11.

Copyright by Lucía González Ruiz, et al. This is an open-access article distributed under the terms of the Creative Commons Attribution License, which permits unrestricted use, distribution, and reproduction in any medium, provided the original author and source are credited.

Source of Support: Nil, Conflict of Interest: None declared. 